\title{
Role of Multi Detector Computed Tomography in Preoperative Evaluation of Middle Ear Cholesteatoma
}

\author{
SARA E. ABD EL-DAYEM, M.Sc.*; EMAD M. MASHALI, M.D.**; MEDHAT M. MANSOUR, M.D.*** and \\ ALSIAGY A. SALAMA, M.D.** \\ The Department of Radiodiagnosis, Tanta Cancer Institute*, Faculty of Medicine, Tanta University** and \\ The Department of Otorhinolaryngology, Faculty of Medicine, Tanta University***
}

\begin{abstract}
Background: Middle ear cholesteatoma is an ectopic squamous stratified epithelium in the middle ear. It is a actually risky disease as it leads to destruction of ossicles and/or walls of middle ear that causes severe complications as hearing loss and brain abscess. Pre-operative assessment of cholesteatoma by Multi-Detectors Computed Tomography (MDCT) is essential for accurate diagnosis and appropriate management to prevent recurrence after surgery.
\end{abstract}

Aim of Study: To assess the diagnostic accuracy of preoperative MDCT of middle ear cholesteatoma with surgical correlation.

Patients and Methods: A prospective study was conducted in Tanta University Hospitals from July 2015 to December 2016 on 30 patients with middle ear cholesteatoma. All patients had a pre-operative MDCT scans. The pre-operative MDCT findings were recorded and correlated with surgical and histopathological results. Sensitivity and specificity of preoperative MDCT findings were calculated considering operative findings as gold standard.

Results: The study included 30 patients, 17 were females and 13 were males with a mean age of 35 years. The diagnostic accuracy of the pre-operative MDCT findings when correlated to intraoperative ones was $100 \%$ in detecting soft tissue mass inside the middle ear, $100 \%$ in detecting the location of cholesteatoma, $100 \%$ in detecting ossicular erosion, $93.3 \%$ in detecting scutum erosion and $100 \%$ in confirming the diagnosis of cholesteatoma proved by post-operative histopathological examination. The mean sensitivity of MDCT in preoperative diagnosis and evaluation of middle ear cholesteatoma was $97.4 \%$ while the mean specificity was $95.8 \%$.

Conclusion: Middle ear cholesteatoma is a distinctive clinical entity with characteristic findings on MDCT scan, that guides in the surgical approach and management plan.

Key Words: Middle ear cholesteatoma-MDCT.

Correspondence to: Dr. Sara E.A. Abd El-Dayem, E-Mail: saraabdeldayem1988@gmail.com

\section{Introduction}

CHOLESTEATOMA is a proliferation of keratinized stratified squamous epithelium in the middle ear. It has a potential osteolytic activity, which may be explained by the existence of collagenase in the periphery of lesion, since bone tissue is composed mainly of collagen $[\mathbf{1 , 2}]$.

There is a debate about the word "cholesteatoma", it originates from "cholesterol" and "tumor", but really it is an epidermoid cyst. its construction doesn't include cholesterol crystals, also it does not have a tumor-like nature $[1,3]$.

According to the etiology, it can be classified into congenital (2\%) and acquired (98\%). The primary and secondary forms are the main types of acquired disease [4,5]

Congenital type arises by trapping of squamous epithelium within the temporal bone during embryogenesis. It grows and leading to conductive hearing loss either through blockade of the Eustachian tube or by damaging the ossicles in middle ear. It typically presents in childhood and rarely existing later in adulthood $[\mathbf{5 , 6}]$.

In primary acquired form the long standing negative pressure in middle-ear resulting from Eustachian tube dysfunction causes sucking back of the tympanic membrane leading to its retraction and erosion of the lateral wall of the epitympanum $[5,7]$. Four theories explain the origin of secondary acquired form namely: Retraction, epithelial invasion, middle ear epithelium metaplasia and hyperplasia of basal cells [7-9].

Pre-operative MDCT imaging has become necessary for diagnosis, recognition of complications 
and planning for the type of surgery. It's also essential for identification of anatomical landmarks in middle ear as tegmen tympani, long process of the incus and epitympanic recess [10-12].

\section{Participants and Methods}

Study design: The study was an observational prospective study.

\section{Participants:}

The current study included 30 patients with middle ear cholesteatoma, 17 were females and 13 were males with a mean age of 35 years. They were referred to Radiology Department at Tanta University Hospitals from Department of Ear, Nose and Throat for radiological assessment and confirmation of clinical diagnosis. The study was approved by the Ethical Committee of Faculty of Medicine in Tanta University from July 2015-Dec. 2016.

\section{Methods:}

All participants were subjected to full history taking, clinical examination and MDCT scanning during their pre-operative assessment and preparation for surgery. The pre-operative scannings were evaluated for the presence of soft tissue mass, its location and extension, scutum erosion, ossicular erosive changes, tegmen tympani affection, integrity of facial nerve and lateral semicircular canals.

Correlation between pre-operative MDCT findings and surgical reports were done for all cases and intraoperative findings were considered as a gold standard.

CT examination of the temporal bone was performed by using Toshiba Aquilion One 320.

Axial scans were obtained through the temporal bone and posterior fossa with the external auditory meatus as a landmark. Axial sections were made parallel to the infraorbital meatal line or hard palate corresponding to the plane of the lateral semicircular canal. Scanning is performed in the standard axial with helical technique $(120 \mathrm{KV}, 200 \mathrm{MA}$, pitch of 0.85 , rotation time of 1 second, section thickness of $0.6 \mathrm{~mm}$, matrix of $512 \times 512$ ).

Window width and window level 1500/500 and multiplanner reconstruction for Axial in $1-2 \mathrm{~mm}$ thickness and Coronal 1-2mm thickness. The subject's head is placed in a neutral position, without chin tilt to approximate the orbito-meatal line. Each reconstruction was tailored to depict structure of common clinical interest. No intravenous contrast was used.

\section{Risks and ethical considerations:}

- All techniques and procedures used in the research have no conflict with religion, law or social rules.

- All participants in this research were submitted to a clearly informed consent.

\section{Histopathologic examination:}

Histopathological examinations of all surgically excised masses were obtained for all patients. Which was the gold standard for final diagnosis.

\section{Statistical analysis:}

The statistical software SPSS Version 17.0 was used for analysis of our data. Quantitive data were described as mean and Standard Deviation (SD). Nominal variables were presented as numbers and percentages. Diagnostic accuracy of pre-operative MDCT and surgical findings were calculated.

\section{Results}

This study included 30 patients with middle ear cholesteatoma, of them $13(43.3 \%)$ were males and $17(56.7 \%)$ were females, their ages ranged from 5 to 65 years with a mean age of 35 years. The most common age group affected by the disease was between 25 and 45 years representing 21 patients $(70 \%)$. The disease was unilateral in 28 patients $(93.3 \%)$ and bilateral in 2 cases $(6.7 \%)$. According to the etiology 29 cases $(96.7 \%)$ had acquired middle ear cholesteatoma and 1 case $(3.3 \%)$ was congenital.

By referring to clinical presentation of our patients, all patients suffered hearing loss, chronic ear discharge was present in $96.7 \%$ of them, other reported symptoms as vertigo, tinnitus, and facial nerve paralysis were presented in $6.7 \%$ of patients for each (Table 1).

Table (1): Distribution of patients according to clinical presentation.

\begin{tabular}{lcc}
\hline Clinical presentation Number of patients & Percentage \% \\
\hline Hearing loss & 30 & 100 \\
Ear discharge & 29 & 96.7 \\
Vertigo & 2 & 6.7 \\
Tinnitus & 2 & 6.7 \\
Facial nerve paralysis & 2 & 6.7 \\
\hline
\end{tabular}

According to location and extension, middle ear cavity including attic was the commonest and seen in 26 cases $(86.7 \%)$, followed by mastoid extension that was found in 25 cases $(83.3 \%)$ then antrum extension which was detected in 20 cases $(66.7 \%)$ and attic cholesteatoma was only present in 4 patients (13.3\%) (Table 2). 
Table (2): Distribution of patients according to CT results of location and extension of middle ear cholesteatoma.

\begin{tabular}{lcc}
\hline $\begin{array}{l}\text { Location and extension } \\
\text { of middle ear cholesteatoma }\end{array}$ & $\begin{array}{c}\text { Number of } \\
\text { patients }\end{array}$ & $\begin{array}{c}\text { Percentage } \\
\%\end{array}$ \\
\hline Attic only & 4 & 13.3 \\
Middle ear cavity including attic & 26 & 86.7 \\
Antrum extension & 20 & 66.7 \\
Mastoid extension & 25 & 83.3 \\
\hline
\end{tabular}

Regarding, MDCT findings of middle ear choleasteatoma, nondependent unenhanced tissue mass was present in $100 \%$ of patients. The most commonly affected ossicle by erosion was the incus that was present in 24 cases $(80 \%)$, followed by eroded scutum that was detected in 23 cases (76.7\%), then eroded malleus which was found in 17 cases $(56.7 \%)$. Tegmen tympani erosion, lateral semicircular canal and facial canal dehiscences were found in $6.7 \%$ of patients for each (Table 3 ).

Pre-operative MDCT and operative findings were identical regarding the presence of tissue mass, location of cholesteatoma, tegmen tympani, malleus and LSC erosions with a 100\% diagnostic accuracy for each. The scutum erosion was found in 23 cases by CT examination while during operation 21 cases were proved to have scutum erosion, so two cases were diagnosed as false positive with $100 \%$ sensitivity, $77.8 \%$ specificity and $93.3 \%$ accuracy. On the other hand, the incus erosion was seen in 24 cases radiologically while during operation it was found in 26 cases with two false negative cases with a sensitivity of $92.3 \%, 100 \%$ specificity and $93.3 \%$ accuracy. Facial canal erosion was identified in 2 cases only by CT, however, two more cases showed facial canal erosion during ear surgery with a sensitivity of $50 \%, 100 \%$ specificity and $93.3 \%$ accuracy (Table 4 ).

In all patients the excised masses were confirmed by histopathological examination and proved to be middle ear cholesteatoma.

Table (3): Distribution of patients according to CT findings of middle ear cholesteatoma.

\begin{tabular}{lcc}
\hline \multirow{2}{*}{ CT findings } & \multicolumn{2}{c}{ Number Percentage } \\
& of patients & $\%$ \\
\hline Tissue mass & 30 & 100 \\
Eroded scutum & 23 & 76.7 \\
Eroded malleus (head) & 17 & 56.7 \\
Eroded incus (long process) & 24 & 80 \\
Tegmen Tympani erosion & 2 & 6.7 \\
Lateral Semicircular canal dehiscence & 2 & 6.7 \\
Facial canal dehiscence & 2 & 6.7 \\
\hline
\end{tabular}

Table (4): Diagnostic accuracy, negative predictive value, positive predictive value, sensitivity and specificity of pre-operative MDCT in relation to intraoperative findings in all patients.

\begin{tabular}{lcccccc}
\hline Features & $\begin{array}{c}\text { MDCT } \\
\text { findings }\end{array}$ & $\begin{array}{c}\text { Operative } \\
\text { findings }\end{array}$ & $\begin{array}{c}\text { Diagnostic } \\
\text { accuracy }\end{array}$ & $\begin{array}{c}\text { Negative } \\
\text { predictive } \\
\text { value }\end{array}$ & $\begin{array}{c}\text { Positive } \\
\text { predictive } \\
\text { value }\end{array}$ \\
\hline Tissue mass & 30 & 30 & 100 & 0 & 100 & 100 \\
Typical location & 29 & 29 & 100 & 0 & 100 & 100 \\
Scutum erosion & 23 & 21 & 93.3 & 100 & 91.3 & 100 \\
Malleus (head) erosion & 17 & 17 & 100 & 0 & 100 & 100 \\
Incus (long process) erosion & 24 & 26 & 93.3 & 66.7 & 100 & 100 \\
Tegmen tympani erosion & 2 & 2 & 100 & 0 & 100 & 100 \\
Facial canal erosion & 2 & 4 & 93.3 & 92.9 & 100 & 100 \\
LSC erosion & 2 & 2 & 100 & 0 & 100 & 100 \\
\hline
\end{tabular}
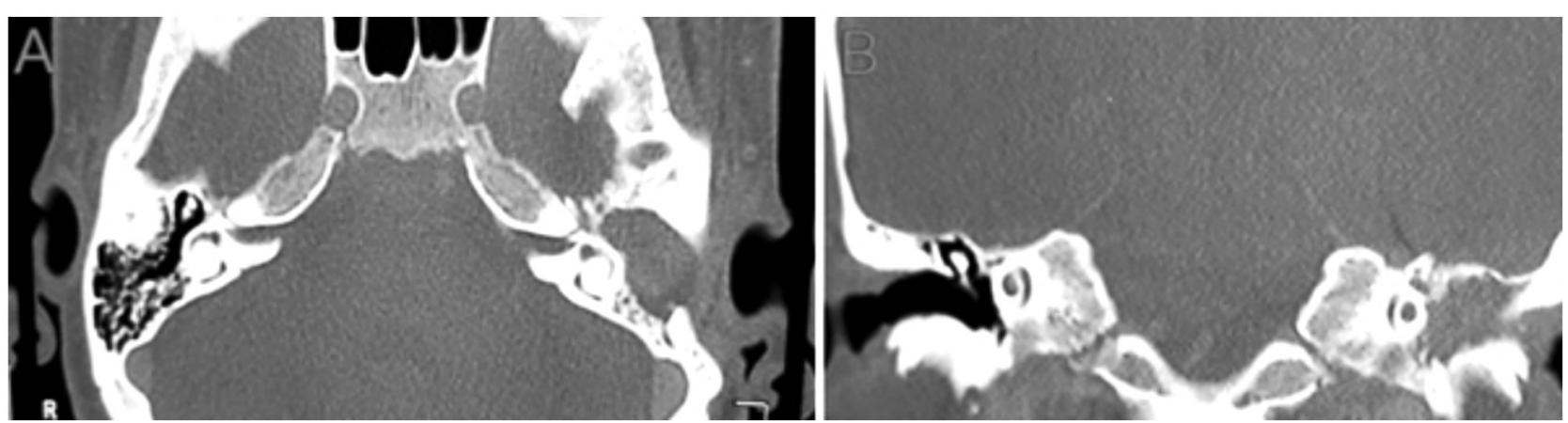

Fig. (1): Male patient aged 46 years proved to have secondary acquired cholesteatoma. MDCT showing soft tissue lesion involving the left middle ear cavity with aditus add antrum, A (axial view): Showing non-visualized left ossicular chain and opacification of left mastoid air cells. B (coronal view): Showing intact scutum. 

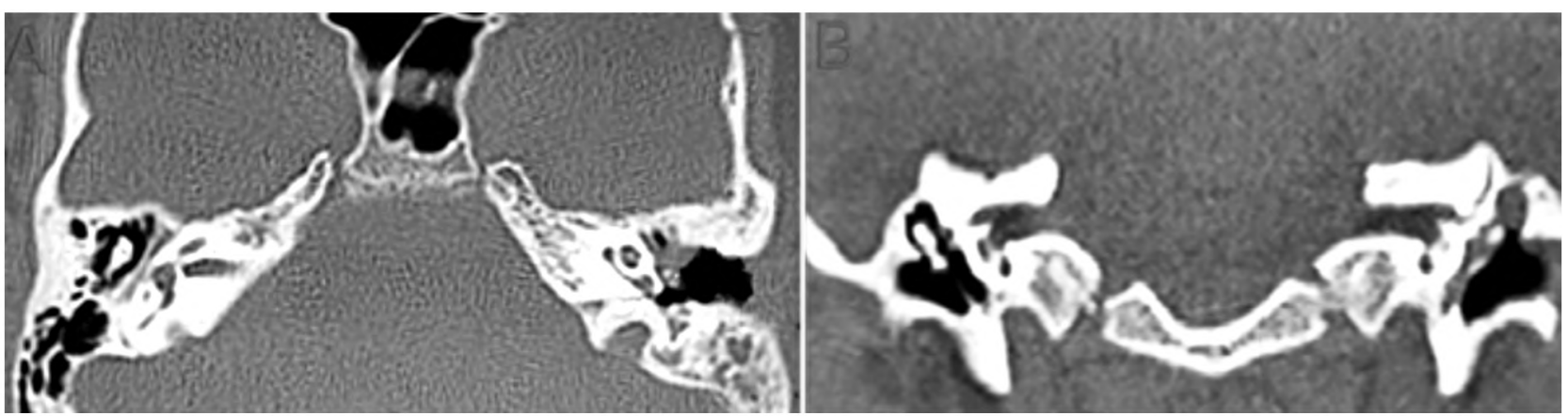

Fig. (2): Male child aged 5 years. MDCT of the temporal bone showing nondependent soft tissue lesion seen in the attic space of the left middle ear cavity with erosion of both head of malleus and process of incus as shown in A (axial view) and blunted eroded scutum in B (coronal view).
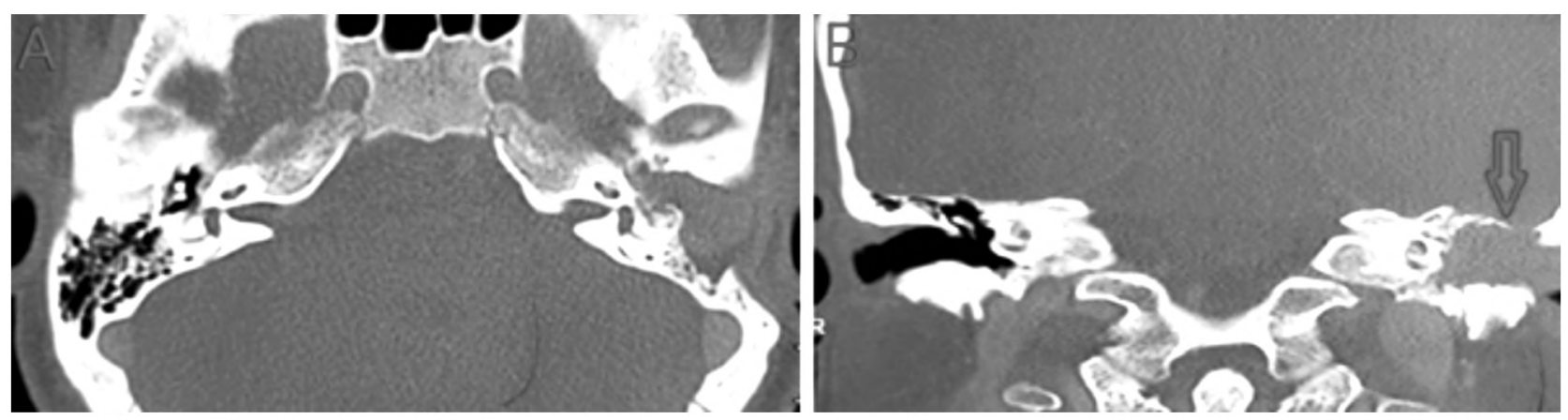

Fig. (3): Female patient aged 44 years. MDCT of the temporal bone showing total opacification of left middle ear cavity and mastoid air cells with non-visualized left ossicular chain with obstruction of the left Eustachian tube as shown in A (axial view). Blunted left scutum and rarified tegmen tympani (red arrow) as shown in B (coronal view).
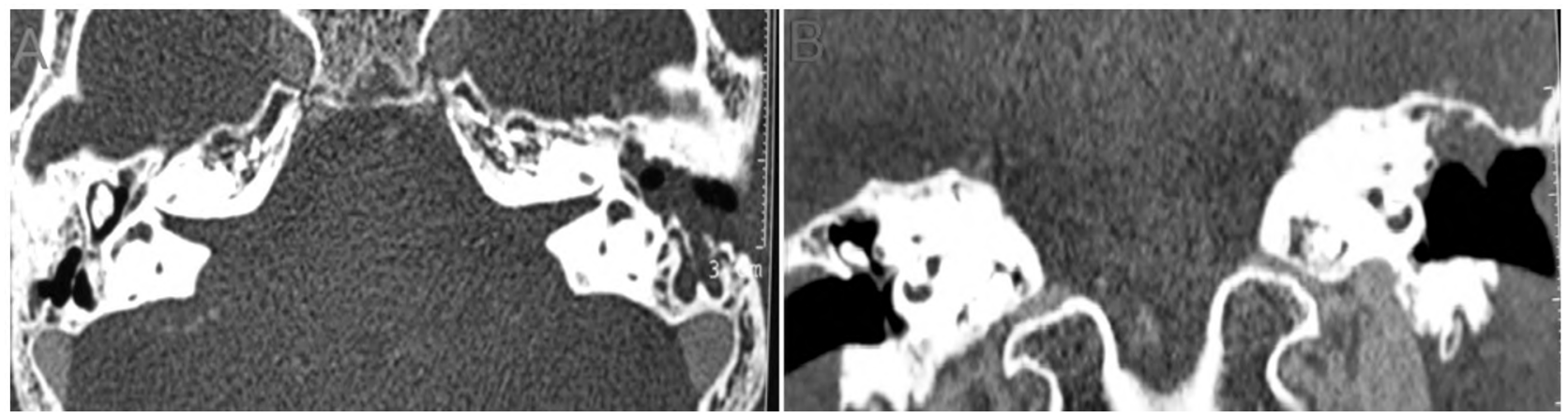

Fig. (4): Female patient aged 55 years, MDCT showing partial opacification of left middle ear cavity with erosion of left ossicular chain with involvement of the sinus tympani in A (axial view). Opacification of attic space with soft tissue lesion with eroded scutum and intact tegmen tympani are seen in B (coronal view).

\section{Discussion}

Cholesteatoma of middle ear causes an erosion of the ossicles and walls of the middle ear cavity, due to an inflammatory response that motivates osteoclastic action. MDCT imaging is required for determination of temporal bone structural landmarks and affords valuable data needed for surgical interference [13-16]. Pre-operative assessment of middle ear cholesteatoma with MDCT is essential in recognition of extension and complications to help the surgeons to select the suitable type of surgery as it's the only method for management of the disease [17,18].

As regard gender distribution, 13 patients were males and 17 were females with a frequency of $43.3 \%$ and $56.7 \%$ respectively. These results were agreed with Choi J., et al., [19] who stated that females were more affected with cholesteatoma than males with a percentage of $69 \%$ to $31 \%$ respectively. In contrast, Thukral C., et al., [20] reported that cholesteatoma had no gender difference. Albera R., et al., [21] and Muzeyyen YB, et 
al., [22] reported that males were more affected than female which was opposite to our results. This disagree may be due to the difference in the number of cases and their gender distribution in the two studies.

In this study, the most affected age group was from 25 to 45 years old as 21 patients were affected with a percentage of $70 \%$. This result was agreed with Thukral C., et al., [20] who stated that cholesteatoma affected frequently patients lower than 30 years old. Also Gaurano JL and Joharjy IA [23] stated that cholesteatoma mostly affected middle age patients and were common between 20 and 35 years old, while Muzeyyen YB, et al., [22] found that the mean age of their study group was 26.5 years with a range from 16 to 67 years old. This was lower than that reported in our study (mean age $=35$ years with a range from 5 to 65 years old). This can be explained by different age distribution in the two studies.

In our study the most common clinical presentations of our patients were hearing loss and ear discharge with a percentage of $100 \%$ and $96.7 \%$ respectively. Other reported symptoms were vertigo, tinnitus and facial nerve paralysis that were presented by $6.7 \%$ of patients for each. These results were agreed with Ghonim M., Ashraf B. [24]who stated that the most two common presentations were ear discharge and hearing loss and the least presented symptom was vertigo.

In the present study the frequency of unilateral cholesteatoma was $93.3 \%$ while bilateral cases were seen in only $6.7 \%$ of patients. This was agreed with Thukral C., et al., [20] who stated that more than $75 \%$ of cholesteatoma was unilateral. On the other side Lynrah ZA, et al., [25] stated that the disease was bilateral in $23.3 \%$ of children while in adults it affected both ears in $30 \%$ of patients. Their higher frequency of bilateral affection may be attributed to the different number and age distribution of cases in the two studies.

In the current study, we found that most of patients had the acquired form of cholesteatoma with a percentage of $96.7 \%$ while only $3.3 \%$ of patients had the congenital form. These results were agreed with the other literatures, for example Flint, et al., [26] mentioned that most cases of cholesteatoma were acquired (92\%) and only $8 \%$ had the congenital type. Also Lynrah ZA, et al., [25]stated that the frequency of congenital type of the disease was $26.7 \%$ which was higher than that reported in our study. This difference may be due to the different number and age distribution of cases in the two studies.

Our findings regarding the distribution of patients according to CT location and extension of the disease. Most of our cases $(86.7 \%)$ presented with mass of middle ear cavity, followed by mastoid extension in $83.3 \%$ of patients, then antral extension with a percentage of $66.7 \%$ and attic cholesteatoma was detected in $13.3 \%$ of patients. Ghonim M., et al., [24] had almost close percentage of attic type of cholesteatoma which was $17.4 \%$, but they disagreed with the extension of the mass to the antrum which was seen in $39.6 \%$ of patients and also mastoid extension that was found in $31.7 \%$ of patients. This difference can be attributed to the different disease stages at time of clinical presentation in the two studies.

In the current study, the presence of soft tissue mass in CT was detected in $100 \%$ of patients, eroded long process of incus was found in $80 \%$ of patients, followed by eroded scutum which was seen in $76.7 \%$ of patients, then eroded malleal head with a frequency of $56.7 \%$ with the least reported findings were for facial canal, LSC and tegmen tympani erosions with the same percentage of $6.7 \%$ for each. In agreement with our results, Gaurano JL, et al., [23] reported that all patients had soft tissue mass in the middle ear cavity also Albera R., and Canale A. [21] stated that the incus was eroded in $78 \%$ of patients and the malleus was only eroded in $20 \%$ of patients. The later frequency was much lower than that found in our series which can be explained by different disease stages at time of clinical presentation. Rogha M., et al., [27] reported that $\mathrm{CT}$ findings of temporal bone included soft tissue mass in the middle ear in $100 \%$ of patients, ossicular erosion $(88 \%)$ and scutum erosion $(72 \%)$ which was agreed with our study.

Late stage cholesteatoma is commonly associated with cranial and extracranial complications frequently in the form of facial nerve paralysis and erosion of the lateral semicircular canal due to the ability of cholesteatoma to erode the bones around it. In this study $6.7 \%$ of patients had facial nerve paralysis and LSC involvement for each. Choi J. and Park YH [19] in their study showed closer results as among their cases, 3.5\% showed facial nerve paralysis and we were agreed also with Ghonim M., et al., [24] who reported LSC involvement in $7 \%$ of patients.

In the current study, the diagnostic accuracy, sensitivity and specificity of pre-operative MDCT 
were $100 \%$ regarding the presence of tissue mass with its typical location, erosions of the head of malleus, LSC and tegmen tympani while they were $93.3 \%, 100 \%, 77.8 \%$ for scutum erosion, respectively. The sensitivity of pre-operative MDCT for detection of incus erosion (long process) was $92.3 \%$ while it was $50 \%$ for facial canal dehiscence with 93.3\% diagnostic accuracy and $100 \%$ specificity for both. Rogha M. et al., [27] were agreed with our study as the sensitivity and the accuracy of the presence of soft tissue mass were $100 \%$, also incus erosion was detected with a sensitivity of $90.6 \%$ and an accuracy of $86.11 \%$. Sensitivity for scutum erosion detection was $96.4 \%$ which was close to our results, while they were disagree as regard LSC erosion where sensitivity was $75 \%$ with an accuracy of $86.1 \%$. Also they reported a sensitivity of $66.7 \%$ and an accuracy of $75 \%$ for facial canal erosion detection, that findings were close to our results. Sethom A, et al., [28] stated that the sensitivity of pre-operative assessment by CT was $90 \%$. Muzeyyen YB, et al., [22] also reported a sensitivity of $91.9 \%$ and a specificity of $94.7 \%$ and Thukral C. et al., [20] found a sensitivity of CT was $89.3 \%$. All these studies were agreed with our findings which showed that the sensitivity of pre-operative CT was $96.6 \%$.

\section{Conclusion:}

Middle ear cholesteatoma is a distinctive clinical entity with characteristic findings on MDCT scan, that guides in the surgical approach and management plan.

\section{References}

1- NEMZEK W.R. and SWARTZ J.D.: Temporal bone: Inflammatory disease in head and neck imaging. 4 th ed. St Louis: Mosby; 1184-99, 2003.

2- FATTERPEKAR G.M., DOSHI A.H., DUGAR M., et al.: Role of 3D CT in the evaluation of the temporal bone. Radiographics, 26 (1): 117-32, 2006.

3- GEBRIM E., GEBRIM E., CHAMMAS M., et al.: Radiologia e diagnóstico por imagem-cabeça e pescoço. $1^{\text {a }}$ ed. Rio de Janeiro: Guanabara Koogan: 52-60, 2010.

4- CRANDALL M.A., NEIBERG M.N. and SEGER K.R.: Neuro-ophthalmic manifestations of a complicated cholesteatoma, Optometry, 81 (3): 137-41, 2010.

5- JUNG J.Y. and CHOLE R.A.: Bone resorption in chronic otitis media: The role of the osteoclast. ORL J. Otorhinolaryngol. Relat. Spec., 64 (2): 95-107, 2002.

6- HIDAKA H., ISHIDA E., KAKU K., et al.: Congenital cholesteatoma of mastoid region manifesting as acute mastoiditis: Case J. Laryngol. Otol., 124 (7): 810-5, 2010.
7- BHUTTA M.F., WILLIAMSON I.G. and SUDHOFF H.H. Cholesteatoma. B.M.J., Mar. 3, 342: d1088, 2011.

8- OLSZEWSKA E., WAGNER M., BERNAL-SPREKELSEN M., et al.: Etiopathogenesis of cholesteatoma. Eur. Arch. Otorhinolaryngol., 261: 6-24, 2004.

9- PRATA A.A., ANTUNES M.L., ABREU C.E., et al.: Estudo comparativo entre achados radiológicos e cirúrgicos na otite média crônica. Arq. Int. Otorrinolaringol., 15: 72-8, 2011.

10- MEHRDAD R., SAYYED M.H., FARHAD M., et al.: Comparison of Pre-operative Temporal Bone CT with Intraoperative Findings in Patients with Cholesteatoma, 26 (74): 7-12, 2004.

11- MARCELO A., WANDERVAL M., EMÍLIA G., et al.: Imaging evaluation of middle ear cholesteatoma: Radiol. Bras., 46 (4), 2013.

12- DAHMANI M., MARX M., DEGUINE O., et al.: Mor phologic examination of the temporal bone by cone beam computed tomography: Comparison with multislice helical computed tomography Annalesfrançaisesdюto-rhinolaryngologie et de Pathologie Cervico-faciale, 128 (5): 272-8, 2011.

13- JULIANO A.F., GINAT D.T. and MOONIS G.: Imaging review of the temporal bone: Part I. Anatomy and inflammatory and neoplastic processes. Radiology, 269: 17-33, 2013.

14- MÁS-ESTELLÉS F., MATEOS-FERNÁNDEZ M., CARRASCOSA-BISQUERT B., et al.: Contemporary nonecho-planar diffusion-weighted imaging of middle ear cholesteatomas. Radiographics, 32: 1197-213, 2012.

15- SETHOM A., AKKARI K., DRIDI I., et al.: Pre-operative CT Scan in middle ear cholesteatoma. Tunis. Med., 3 (89): 248-53, 2011.

16- MOHAMMADI G.H., NADERPOUR M. and MOUSAVIAGDAS M.: Ossicular Erosion in Patients Requiring Surgery for Cholesteatoma. Iranian Journal of Otorhinolaryngology, 4 (68): 125-8, 2012.

17- AYACHE D., DARROUZET V., DUBRULLE F., et al.: Imaging of non-operated cholesteatoma: Clinical practice guidelines. Eur. Ann. Otorhinolaryngol. Head Neck Dis., 129: 148-52, 2012.

18- ESHETU T. and AYGUN N.: Imaging of the temporal bone: A symptom-based approach. Semin. Roentgenol., 48: 52-64, 2013.

19- CHOI J. and PARK Y.H.: Facial nerve paralysis in patients with chronic ear infections: Surgical outcomes and radiologic analysis. Clinical and Experimental Otorhinolaryngology, 8 (3): 218-23, 2015.

20- THUKRAL C., SINGH A., SINGH S., et al.: Role of High Resolution Computed Tomography in Evaluation of Pathologies of Temporal Bone. J.C.D.R., 10-7860, 2015.

21- ALBERA R., CANALE A., PIUMETTO E., et al.: Ossicular chain lesions in cholesteatoma: ACTA otorhinolaryngologica ITALICA, 32: 309-13, 2012.

22- MUZEYYEN Y.B., CIHAN A.O., RAMAZAN G., et al.: An Evaluation of Pre-operative Computed Tomography 
on Patients with Chronic Otitis Media. Indian J. Otolaryngol. Head Neck Surg., 64 (1): 67-70, 2012.

23- GAURANO J.L. and JOHARJY I.A.: Middle ear cholesteatoma: Characteristic CT findings in 64 patients. Ann. Saudi Med., 24 (6): 442-7, 2004.

2- GHONIM M., ASHRAF B. and ABDEL RAZEK A.: Computed Tomography Staging of Middle Ear Cholesteatoma. Pol. J. Radiol., 80: 328-33, 2015.

25- LYNRAH Z.A., BAKSHI J., PANDA N.K., et al.: Aggressiveness of Pediatric Cholesteatoma. Do We Have an
Evidence? Indian J. Otolaryngol. Head Neck Surg., 65 (3): 264-8, 2013.

26- FLINT P.W., LUND V.J., THOMAS J.R., et al.: Cummings otolaryngology head and neck surgery sixth edition, Vol. 4, No. 139, 2139: 56, 2015.

27- ROGHA M., HASHEMI S., DADGOSTAR A., et al.: Comparison of Pre-operative Temporal Bone CT with Intraoperative Findings in Patients with Cholesteatoma. Iranian Journal of Otorhinolaryngology, Vol. 26 (1), No. $74,2014$.

\section{دور الآثعة المقطعية متعددة المقاطع فى تقيييم كولستياتوما الآذن الوسطى

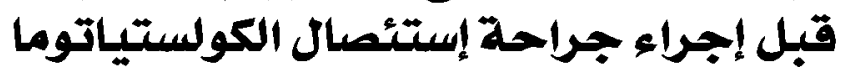

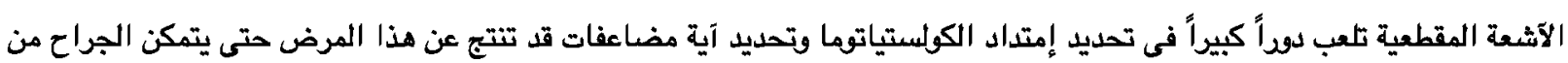

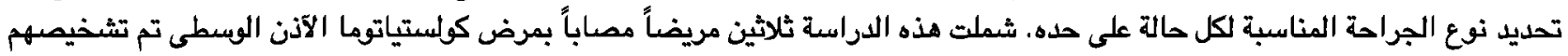

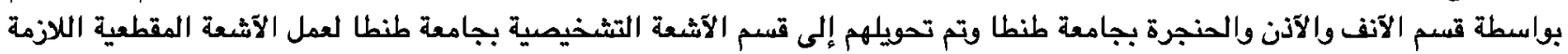

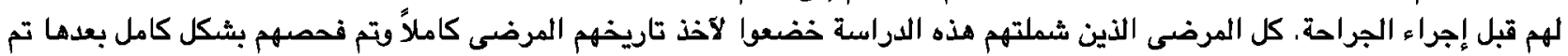

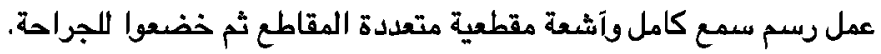

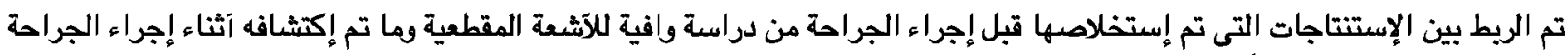

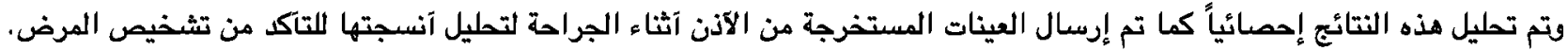

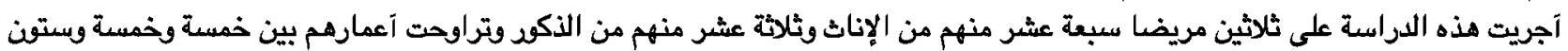

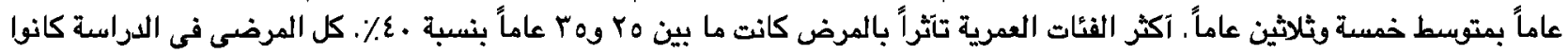

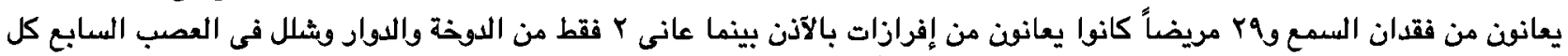

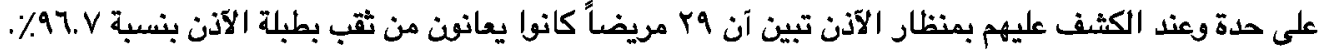

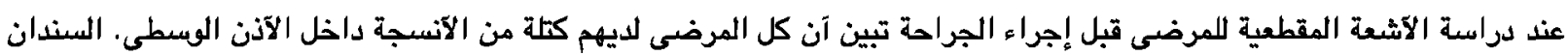

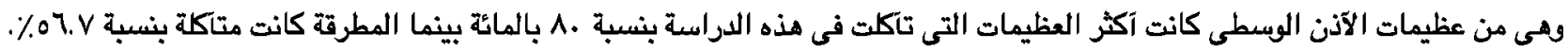

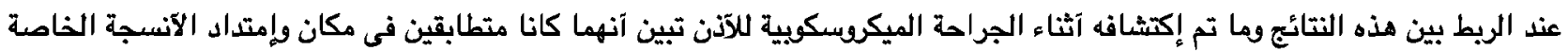

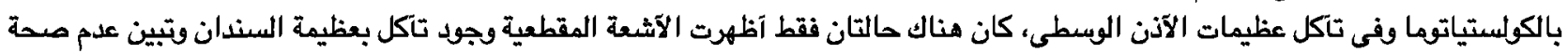

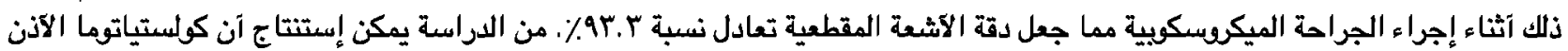

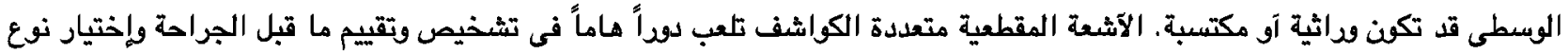

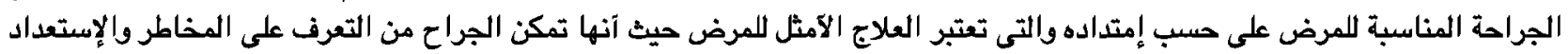
لإمكانية تجنبها على قدر الإمكان. 